\title{
Sociodemographic Factors' Association with Community-Dwelling Older Adults' Psychosocial Wellbeing: The Greek Context
}

\author{
Dimitrios Papadopoulos \\ Department of Psychology, University of Crete, Gallos University Campus, Rethymno, Greece \\ Email: d.papadopoulos@uoc.gr
}

How to cite this paper: Papadopoulos, D. (2020). Sociodemographic Factors' Association with Community-Dwelling Older Adults' Psychosocial Wellbeing: The Greek Context. Psychology, 11, 340-363.

https://doi.org/10.4236/psych.2020.112022

Received: January 19, 2020

Accepted: February 17, 2020

Published: February 20, 2020

Copyright $\odot 2020$ by author(s) and Scientific Research Publishing Inc. This work is licensed under the Creative Commons Attribution International License (CC BY 4.0).

http://creativecommons.org/licenses/by/4.0/

\begin{abstract}
This cross-sectional study aimed to examine the associations of sex, age, marital status, education attainment, religious involvement, perceived health, and income with psychosocial domains of wellbeing assessed using the $\mathrm{Ge}$ riatric Depression Scale (GDS-15), Satisfaction with Life Scale (SWLS), Subjective Happiness Scale (SHS), and Spiritual Wellbeing Scale (SWBS). In total, 356 community-dwelling older adults from Greece, aged 65 years and above, completed a sociodemographic survey and psychosocial self-reported questionnaires. Bivariate and stepwise regression analyses helped to determine the sociodemographic factors' associations with their wellbeing. These background predictors together explained a significant part of the variance in scores on all psychosocial domains: 31\% for GDS-15, 44\% for SHS, $63 \%$ for SWLS, and 58\% for SWBS. After controlling for other sociodemographic factors, both being healthy and attending church were related to better outcomes in the domains of happiness, life satisfaction, and spiritual wellbeing. Higher income was related to better outcomes on all domains of wellbeing, while higher educational attainment was related to worse outcomes on all domains of wellbeing. Marital status was positively related to depression only. Thus, successful aging approaches may benefit from a deeper understanding of wellbeing and its predictors, which are essential to improve older adults' psychosocial wellness.
\end{abstract}

\section{Keywords}

Aging, Happiness, Life Satisfaction, Sociodemographic Factors, Wellbeing

\section{Introduction}

Population aging represents one of the most important contemporary demo- 
graphic trends worldwide, with the number of people aged 80 years and older expected to have increased by nearly 1 billion globally by the year 2050 (United Nations, Department of Economic and Social Affairs, Population Division, 2017). Dealing with the challenges posed by an aging population is difficult in many European societies, where a growing population of older adults is coupled with a shrinking pool of working-age adults, placing increasing strain on health care resources and other social services (Lutz, O'Neill, \& Scherbov, 2003). These challenges are reflected in European public policy, which has begun to prioritize the goals of encouraging healthy and successful aging (European Commission, Economic and Financial Affairs, 2018). Given these considerations, there has been an increasing recognition of the importance of examining wellbeing indicators, with studies indicating an association between health and good functioning, leading to several positive life outcomes including longevity and lower rates of morbidity and mortality, as well as decreased health care needs, particular at older ages (Jivraj, Nazroo, Vanhoutte, \& Chandola, 2014). Furthermore, the lifespan literature highlights that although absence of illness and disability is crucial predictors of maintained and improved wellbeing (Staptoe, Deaton, \& Stone, 2015), individual wellness is also affected by various social and demographic variables. These include sex, age, income, education, marital status, social connectedness, and religious involvement, as well as certain well-known psychological characteristics, including sense of coherence and personality traits, factors that also change with age (Von Humboldt, Leal, \& Pimenta, 2015). However, the findings provide no consensus regarding the severity of impact that age has on wellbeing. Some studies suggest that wellbeing tends to improve as people age, compared to middle life (Carstensen, Fung, \& Charles, 2003), while other studies suggest that such a U-curve of life satisfaction cannot be accepted worldwide, especially not in low-income countries (Frijters \& Beaton, 2008).

The most recent Greek census, conducted in 2011, reflects these global trends. Older adults aged 65 and above comprised nearly $20 \%$ of the population in 2011, one of the highest rates of older people in Europe (Eurostat, 2015). With life expectancy having risen dramatically to 83.7 years for women and 78.8 years for men (from 76.5 years and 72.2 years, respectively, 30 years ago) coupled with a sharply declining birth rate, this proportion is expected to continue to rise in the coming years (Hellenic Statistical Authority, 2019a). In addition to these changing demographics, Greek older adults are especially vulnerable to social disparities in comparison to their counterparts elsewhere in Europe, due to the country's continuing economic crisis and longstanding issues with the health system (Thøgersen-Ntoumani et al., 2011). Furthermore, an increased prevalence of psychosocial problems in middle-aged and older adults has been linked to the economic crisis (Economou, Madianos, Peppou, Patelakis, \& Stefanis, 2013), which may partially explain the trends observed in the current study, since the 2010 financial recession affected Greece particularly harshly. 
Despite the large body of research related to aging and wellbeing, there have been relatively few studies of these processes among the Greek population specifically, and their findings are mixed. Cross-national studies have generally indicated that Greek people tend to report lower levels of happiness than do other Europeans (Oishi, Diener, Lucas, \& Suh, 1999; Diener, Diener, \& Diener, 2009), while also showing that regional and wealth-related inequalities in wellbeing are substantially less pronounced in Greek society than in other European countries (Hagerty \& Veenhoven, 2003). In addition, a cross-national study by Veenhoven (2007) found that Greece has consistently shown stable values for life satisfaction since 1981, suggesting that Greek people's wellbeing might be a reflection of cultural components that affect the expression of happiness. There have been a few small-scale studies of wellbeing in Greek older adults, which have largely echoed findings in other countries, including tying positive outcomes to reported positive social ties with family (Efklides, Kalaitzidou, \& Chankin, 2003) and healthy psychological attachment styles (Kafetsios \& Sideridis, 2006). Furthermore, previous studies investigating social profiles of elderly adults in Greece have indicated high illiteracy levels (Kinsella \& Velkoff, 2001; Zarifis, 2016) and low-income positions (Koutsampelas, 2012), which may have severe adverse effects on various aspects of their subjective wellbeing.

Nevertheless, the Greek population remains seriously underrepresented in the literature on wellbeing in older adulthood. Although many elements of healthy aging would appear to be cross-culturally applicable, certain elements of Greek culture and demography may affect these relationships in ways that have not yet been fully elucidated. For instance, compared with Europe generally, the Greek culture has been characterized as relatively less individualistic and more collectivistic (Kalogeraki, 2009), which may indicate enhanced importance of family structure and connectedness for Greek older adults. In addition, religious orientation, on both the personal and cultural levels, is related to wellbeing outcomes (Hayward \& Elliott, 2014). In Greece, the religious culture is primarily Orthodox Christian, in contrast with the historical dominance of Catholicism and Protestantism throughout most of Europe. However, Orthodox individuals and societies have been poorly represented in wellbeing research, leaving questions open about the extent to which religion affects wellbeing in such contexts. Finally, Greek society in general, and Greek older adults in particular, have faced substantially greater socioeconomic challenges in the past decade than Europeans as a whole, which may have implications for the dynamics of wellbeing within this population (Foscolou et al., 2017).

In sum, although the study of wellbeing in older adulthood is burgeoning with important implications for society, the Greek population remains severely underrepresented in the empirical literature. Furthermore, there are no consistent findings on the relationship between sociodemographic factors and the psychosocial domains of wellbeing, either worldwide or in Greece. Therefore, this study aimed to address these gaps in the gerontological literature by examining the associations between certain sociodemographic predictors and a range of 
wellbeing outcomes among community-dwelling older adults in later life, as assessed using the Geriatric Depression Scale (GDS-15), Satisfaction with Life Scale (SWLS), Subjective Happiness Scale (SHS), and Spiritual Wellbeing Scale (SWBS). It was anticipated that wellbeing in this sample would be related to the same types of sociodemographic background factors, including poverty, education, and income, as have been found in previous researches in other cultural contexts (George, 2010; Gobbens \& Remmen, 2019; Gwozdz \& Sousa-Poza, 2010).

\section{Methods}

\subsection{Participants and Procedure}

A cross-sectional survey study was conducted from December 2018 to April 2019 in the metropolitan area of Athens, Greece. The sample included 356 older adults aged 65 years and above. Of them, 160 were men and 196 were women, and their ages ranged from 65 to $85(M=71.25 ; S D=5.2)$. Participants were recruited from the Aging Department of the Greek Association of Mental Health for Children and Adults. The inclusion criteria were as follows: 1) being aged between 65 and 85 years, 2) having sufficient cognitive ability, as defined with a score of less than or equal to 24 on the Mini-Mental State Examination (MMSE) (Fountoulakis, Tsolaki, Chantzi, \& Kazis, 2000), 3) living autonomously in the community and being capable of managing their own care needs, 4) absence of severe mental disorders, and 5) willing to cooperate and give informed consent to participate in the study. Participants with previous diagnosis of Parkinson's disease, dementia, and/or severe sensory impairments were also excluded from the study. Moreover, 38 participants were excluded for submitting forms with missing or incorrect responses.

\subsection{Ethical Approval}

All individuals contacted were informed about the purpose of the study; all individuals who agreed to participate signed a consent form. The study abided by the principles outlined in the Declaration of Helsinki and was approved by the Ethics Committee of the Greek Association of Mental Health for Children and Adults (approval number 3826/09.2018).

\subsection{Research Instruments}

\subsubsection{Sociodemographic Form}

The sociodemographic form was a brief, non-validated self-report survey designed by the author specifically for this study. Participants were asked to complete this sociodemographic questionnaire, with items on: 1$) \operatorname{sex}(0=$ male, $1=$ female), 2) age (in years), 3$)$ marital status ( $0=$ never married, $1=$ married, $2=$ divorced, 3 = widowhood $), 4)$ education ( 0 = never went to school, $1=$ elementary school, 2 = high school, 3 = secondary education, 4 = university and above), 5) church attendance $(0=$ weekly church attendance, $1=$ lack of weekly church 
attendance); 6) perceived health status assessed on a six-point Likert-type scale from "very bad" to "very good", and 7) monthly income, divided into four main categories.

\subsubsection{Cognitive Assessment}

The MMSE was used as a screening test to detect cognitive function in elderly people, in order to assess orientation, registration, attention and calculation, recall, language, visual-spatial and motor coordination, and ability to follow simple commands (Folstein, Folstein, \& McHugh, 1975; Greek version: Fountoulakis et al., 2000). The MMSE is also used to identify early physiological changes in cognition related to aging and, in addition, to document responses to and effectiveness of interventions and treatments. An MMSE score of less than 24 is defined as "normal" cognition, while participants with an MMSE score of greater than 24 are defined as having cognitive impairment (Creavin et al., 2016). Several studies have stressed the good psychometric properties of MMSE for evaluating cognitive functions among older adults (Baek, Kim, Park, \& Kim, 2016; Tombaugh \& McIntyre, 1992). The Cronbach's alpha in our sample for the scale was 0.86 .

\subsubsection{Psychosocial Wellbeing Assessment}

The Geriatric Depression Scale (Short Version, GDS-15) (Yesavage, Brink, \& Rose, 1982; Greek version by: Fountoulakis, Tsolaki, \& Iakovides, 1999) is a self-report assessment tool used to measure older adults' perceived emotional state and depressive symptoms, and has been tested extensively in research studies and clinical settings (Sheikh \& Yesavage, 1986). It comprises a simple response format (yes $=0$, no $=1$ ), with scores ranging from 0 to 15 . A cutoff score of 5 or higher on GDS is suggestive of depression, while one of 0 to 4 indicates normal subjective emotional state. In this study, the Cronbach's alpha for this scale was 0.91 .

The Satisfaction with Life Scale (SWLS; Diener, Emmons, Larsen, \& Griffin, 1985; Greek version: Lyrakos et al., 2013) is a self-administrated instrument to assess individuals' global cognitive judgment of life satisfaction and has been used widely for research purposes. This scale has five items with multiple response alternatives rated on a Likert-type scale ranging from "highly agree" to "highly disagree." Overall scores thus range from 0 to 35, with higher scores indicating that one's life is enjoyable. In general, SWLS scores can be interpreted as follows: 5 - 9 extremely dissatisfied, 10 - 14 dissatisfied, 15 - 19 slightly below average in life satisfaction, 20 - 24 moderately satisfied, 25 - 29 mostly satisfied, and 30 - 35 highly satisfied. In the current study, the Cronbach's alpha was 0.87 for this scale.

The Subjective Happiness Scale (SHS; Lyubomirsky \& Lepper, 1999; Greek version: Avgoustaki, Dimitriadou, \& Stalikas, 2012) is a four-item self-administrated measure widely used to assess overall levels of subjective happiness, rated on a seven-point scale using statements in which participants either simply rate 
themselves or compare themselves to others concerning how happy or unhappy they are. Total score on SHS is computed by averaging responses to the four items, with higher scores reflecting greater subjective happiness. The Cronbach's alpha was 0.79 for this scale in the current study.

The Spiritual Wellbeing Scale (SWBS; Bufford, Paloutzian, \& Ellison, 1991) is a 20-item self-report instrument for measuring general subjective state of spiritual wellbeing, where participants answer on a 6-point Likert-type scale ranging "strongly agree" to "strongly disagree." This psychometric tool includes two 10-item subscales: 1) religious wellbeing, describing the respondent's perceived relationship with God; and 2) existential wellbeing, indicating the respondent's perceived life satisfaction and purpose of life. The overall score on SWBS ranges from 20 to 120, with higher scores reflecting higher perceptions of spiritual wellbeing and quality of life. This scale was translated into Greek using the standard method of forward/backward-translation (Beaton, Bombardier, Guillemin, \& Ferraz, 2000). The overall Cronbach's alpha was 0.81 for this scale in this study.

\subsection{Data Analysis}

A series of descriptive and inferential statistical analyses were conducted to address the research questions of the study. Descriptive comparisons were initially conducted based on sex (male or female) and age (young-old, aged 65 - 75 years; old-old, aged 75 years and above). Due to the low frequency of old-old participants compared to those in the young-old age group, group comparisons were conducted by sex only. The associations between the sociodemographic factors and the psychosocial domains of GDS-15, SHS, SWLS, and SWBS were examined using Eta in order to determine the associations between the six categorical variables (sex, marital status, education, income, perceived health status, and church attendance) and the dependent variables. The associations between the continuous variable (age, in years) and the psychosocial variables were examined using Pearson's correlations (see Table 3).

Moreover, before multiple regression, with the psychosocial domains of four scales as dependent variables and all sociodemographic factors as independent variables was performed, dummies for sex (" 1 " women and " 0 " men), marital status ("1" married or cohabiting and "0" otherwise), and frequency of church attendance (" 0 " weekly church attendance and " 1 " lack of weekly church attendance) were adopted, as used in other studies (Gobbens \& Remmen, 2019). Moreover, effects of age, education, and perceived health status were included in these regression analyses. For monthly income, the interval midpoint of the answering categories was employed (see Table 1), and this factor was examined as a quantitative variable after the unit was modified to euros. For each outcome (GDI-15, SWLS, SWHS, and SWBS), a forward stepwise model was constructed, in which all predictors (age, sex, marital status, education, church attendance, perceived health status, and monthly income) were entered, and those with significant coefficient estimates were retained. All continuous predictor variables 
Table 1. Participant demographics by sex and age group.

\begin{tabular}{|c|c|c|c|c|c|c|c|c|}
\hline & \multicolumn{4}{|c|}{ Sex } & \multicolumn{4}{|c|}{ Age group } \\
\hline & \multicolumn{2}{|c|}{ Male } & \multicolumn{2}{|c|}{ Female } & \multicolumn{2}{|c|}{$\begin{array}{c}\text { Young-old } \\
(65-75 \text { years })\end{array}$} & \multicolumn{2}{|c|}{$\begin{array}{c}\text { Old-old } \\
(75-85 \text { years })\end{array}$} \\
\hline & $\mathrm{N}$ & $\%$ & $\mathrm{~N}$ & $\%$ & $\mathrm{~N}$ & $\%$ & $\mathrm{~N}$ & $\%$ \\
\hline \multicolumn{9}{|l|}{ Marital status } \\
\hline Single & 0 & 0 & 4 & 1,12 & 4 & 1.12 & 0 & 0 \\
\hline Married & 132 & 82.5 & 120 & 61.22 & 200 & 70.42 & 52 & 72.22 \\
\hline Divorced & 8 & 5 & 20 & 10.20 & 24 & 8.45 & 4 & 5.56 \\
\hline Widowed & 20 & 12.5 & 52 & 26.53 & 56 & 19.72 & 16 & 22.22 \\
\hline \multicolumn{9}{|l|}{ Education } \\
\hline None & 4 & 2.5 & 12 & 6.12 & 8 & 2.82 & 8 & 11.11 \\
\hline Elementary school & 84 & 52.5 & 120 & 61.22 & 148 & 52.11 & 56 & 77.78 \\
\hline High school (3 years) & 24 & 15 & 24 & 12.24 & 44 & 15.49 & 4 & 5.56 \\
\hline Secondary (6 years) & 28 & 17.5 & 20 & 10.20 & 44 & 15.49 & 4 & 5.56 \\
\hline University degree & 20 & 12.5 & 20 & 10.20 & 40 & 14.08 & 0 & 0 \\
\hline \multicolumn{9}{|l|}{ Monthly income } \\
\hline Less than $€ 500$ & 8 & 5 & 40 & 20.41 & 36 & 12.68 & 12 & 16.67 \\
\hline$€ 500$ to 800 & 52 & 32.5 & 76 & 38.78 & 100 & 35.21 & 28 & 38.89 \\
\hline$€ 800$ to 1000 & 60 & 37.5 & 36 & 18.37 & 72 & 25.35 & 24 & 33.33 \\
\hline More than $€ 1000$ & 40 & 25 & 44 & 22.45 & 76 & 26.76 & 8 & 11.11 \\
\hline \multicolumn{9}{|l|}{ Church attendance } \\
\hline Yes & 132 & 82.5 & 132 & 67.35 & 216 & 76.06 & 48 & 66.67 \\
\hline No & 28 & 17.5 & 64 & 32.65 & 68 & 23.94 & 24 & 33.33 \\
\hline \multicolumn{9}{|l|}{ Perceived health status } \\
\hline Very bad & 4 & 2.50 & 12 & 6.12 & 8 & 2.82 & 8 & 11.11 \\
\hline $\mathrm{Bad}$ & 20 & 12.5 & 32 & 16.33 & 36 & 12.68 & 16 & 22.22 \\
\hline Moderate & 28 & 17.5 & 68 & 34.69 & 84 & 29.58 & 12 & 16.67 \\
\hline Good & 64 & 40 & 36 & 18.37 & 80 & 28.17 & 20 & 27.78 \\
\hline Very good & 40 & 25 & 24 & 12.24 & 52 & 18.31 & 12 & 16.67 \\
\hline Unknown & 4 & 2.5 & 24 & 12.24 & 24 & 8.45 & 4 & 5.56 \\
\hline
\end{tabular}

were mean-centered for analysis, to reduce the risk of multicollinearity and facilitate interpretation of the coefficient estimates. Finally, for each model related to the psychosocial domains of GDS-15, SWLS, SHS, and SWBS, the explained variance, $\mathrm{R}^{2}$, was determined.

Correlation analysis between the four dependent variables of the GDI-15, SWLS, SWHS, and SWBS were also examined as part of the descriptive analyses, to determine any significant relationship. Correlation coefficients were inter- 
preted as follows: $|\mathrm{r}| \geq 0.9$-very strong correlation; $0.7 \leq|\mathrm{r}|<0.9$-strong correlation; $0.5 \leq|\mathrm{r}|<0.7$-moderately strong correlation; $0.3 \leq|\mathrm{r}|<0.5$-weak correlation; and $|\mathrm{r}| \geq 0.3$-very weak (negligible) correlation.

All the statistical analyses were conducted using SPSS version 25.0 (IBM Corporation, Armonk, NY, USA), and the level of statistical significance was set at $p$ $<0.05$.

\section{Results}

\subsection{Descriptive Statistics for Participant Characteristics}

A total of 365 elderly individuals from Greece responded to the survey. The majority were women, married, and belonged to the young-old age group. With regards to marital status, there was a prevalence of married (70.8\%) and widowed (20.2\%) respondents, and a lower percentage of single (1.12\%), and divorced individuals (7.8\%). Most participants had an elementary school education (57.3\%), with men being somewhat more likely than women to have advanced beyond this level (45.0\% vs. $32.7 \%)$, and old-old participants less likely than young-old participants to have advanced further (11.2\% vs. $45.1 \%)$. In terms of income, most participants reported monthly incomes in the middle brackets of $€ 500$ to $€ 800$ (36.0\%) or $€ 800$ to $€ 1000$ (30.0\%), and more women than men had monthly incomes less than $€ 500$ ( $20.4 \%$ vs. $5.0 \%)$. Nearly three-quarters of participants reported attending church (74.2\%), and attendance was somewhat higher among men $(82.5 \%)$ than women $(67.4 \%)$, and somewhat higher among the young-old $(76.1 \%)$ than the old-old (66.7\%). Overall, exactly half of the participants who responded to the health rating question reported being in good or very good health $(50.0 \%)$, while $20.7 \%$ rated their health as bad or very bad, and the remaining $29.3 \%$ reported moderate health. Men tended to report their health as better than women, with $66.7 \%$ of men rating their health as good or very good compared with only $34.9 \%$ of women. Old-old participants were more likely to rate their health as bad or very bad in comparison with the young-old $(33.3 \%$ vs. $15.5 \%)$. A complete description of demographics and health ratings by sex and age group are presented in Table 1 .

Table 2 presents descriptive statistics for the outcome variables by sex, with mean comparison statistics. There were significant differences between men and women in terms of SWLS and SWBS (in each case $p<0.05$ ), with men reporting

Table 2. Descriptive statistics for dependent variables.

\begin{tabular}{cccccccc}
\hline & Mean (SD) & Range & Male (SD) & Female (SD) & $\mathrm{t}$ & $\mathrm{p}$ & $95 \% \mathrm{CI}$ \\
\hline GDS-15 & $3.94(3.21)$ & $0-15$ & $3.72(0.54)$ & $4.12(0.43)$ & -0.57 & $>0.05$ & $(-1.77,0.97)$ \\
SWLS & $26.12(26.1)$ & $1-35$ & $28.35(0.74)$ & $24.3(1.03)$ & 2.9 & $*<0.05$ & $(1.23,6.54)$ \\
SHS & $18.29(18.2)$ & $1-28$ & $18.97(0.62)$ & $17.73(0.6)$ & 1.4 & $>0.05$ & $(-0.49,2.98)$ \\
SWBS & $83.61(19.4)$ & $1-120$ & $90.27(2.80)$ & $78.18(2.75)$ & 3.04 & $*<0.05$ & $(4.19,20.01)$ \\
\hline
\end{tabular}

Notes: ${ }^{*} p<0.05$; GDS-15, Geriatric Depression Scale; SWLS, Satisfaction with Life Scale; SHS, Subjective Happiness Scale; SWBS, Spiritual Wellbeing Scale; SD, standard deviation; CI, confidence interval. 
better outcomes on both measures. There were no significant sex differences on the GDS-15 or SHS measures (in each case $p>0.05$ ).

\subsection{Bivariate Associations between Sociodemographic Factors and Psychosocial Wellbeing}

Table 3 presents the bivariate associations between the independent sociodemographic factors (sex, age, marital status, education, income, perceived health status, and church attendance) and the dependent psychosocial variables of GDS-15, SWLS, SHS, and SWBS using Eta. In relation to sex, being a woman was negatively associated with SWLS and SWBS; however, it was not associated with GDS-15 or SHS. Marital status was positively associated with GDS-15 scores $(p<0.05)$, with married or cohabiting participants reporting lower depressive symptoms.

Educational attainment had a negative association with scores on all domains of psychosocial wellbeing. Significant associations between the respondents' monthly income and their scores on the GDS-15 $(p<0.05)$, SWLS $(p<0.05)$, SHS $(p<0.01)$, and SWBS $(p<0.05)$ were found. Self-rated health showed significant associations with SWLS, SHS, and SWBS scores (in each case $p<0.05$ ) but did not influence GDS-15 scores. Significant associations of church attendance with SWLS and SHS (in each case $p<0.05)$ and SWBS scores $(p<0.01)$ were also found, indicating that people who attended church also reported a greater sense of spiritual wellbeing and enjoyed their lives more. Contrary to expectations, the respondents' age did not correlate significantly with any of the four dependent psychosocial variables.

Finally, Table 4 demonstrates the correlations between the four dependent

Table 3. Associations between sociodemographic factors and psychosocial wellbeing variables of GDS-15, SWLS, SHS, and SWBS.

\begin{tabular}{cccccccc}
\hline & Sex & Age & $\begin{array}{c}\text { Marital } \\
\text { status }\end{array}$ & Education & Income & $\begin{array}{c}\text { Perceived } \\
\text { health status }\end{array}$ & $\begin{array}{c}\text { Church } \\
\text { attendance }\end{array}$ \\
\hline GDS-15 & 0.05 & 0.04 & $0.07^{*}$ & $-0.04^{*}$ & $0.03^{*}$ & 0.06 & 0.04 \\
SWLS & $-0.14^{*}$ & 0.03 & 0.05 & $-0.05^{*}$ & $0.07^{*}$ & $0.10^{*}$ & $0.06^{*}$ \\
SHS & 0.04 & 0.06 & 0.04 & $-0.04^{*}$ & $0.09^{* *}$ & $0.09^{*}$ & $0.05^{*}$ \\
SWBS & $-0.16^{*}$ & 0.05 & 0.04 & $-0.06^{*}$ & $0.07^{*}$ & $0.07^{\star}$ & $0.09^{* *}$ \\
\hline
\end{tabular}

Notes: ${ }^{*} p<0.05 ;{ }^{* *} p<0.01$; GDS-15, Geriatric Depression Scale-Short Form; SWLS, Satisfaction with Life Scale; SHS, Satisfaction Happiness Scale; SWBS, Spiritual Wellbeing Scale.

Table 4. Means, standard deviation, and pearson's correlations for dependent psychosocial variables of GDS-15, SWLS, SHS, and SWBS.

\begin{tabular}{cccccc}
\hline & Mean (SD) & 1 & 2 & 3 & 4 \\
\hline GDS-15 & $3.94(3.21)$ & 1.00 & & & \\
SWLS & $26.12(26.1)$ & $-0.53^{\star *}$ & 1.00 & & \\
SHS & $18.29(18.2)$ & $-0.62^{\star}$ & $0.77^{\star}$ & 1.00 & \\
SWBS & $83.61(19.4)$ & $-0.47^{\star}$ & $0.87^{\star}$ & $0.70^{\star}$ & 1.00 \\
\hline
\end{tabular}

Notes: ${ }^{*} p<0.05 ;{ }^{* *} p<0.01$; GDS-15, Geriatric Depression Scale-Short Form; SWLS, Satisfaction with Life Scale; SHS, Satisfaction Happiness Scale; SWBS, Spiritual Wellbeing Scale; SD, standard deviation. 
wellbeing variables. As expected, the correlation coefficients were found to be moderate to high between spiritual wellbeing and subjective happiness $(\mathrm{r}=0.70$; $p<0.05)$ and life satisfaction measures $(\mathrm{r}=0.87 ; p<0.05)$, while symptoms of depression (GDS-15) were negatively associated with each of the psychosocial wellbeing measures.

\subsection{Regression Analysis}

Forward stepwise regression models were used to estimate the associations between the six sociodemographic factors as independent variables and the four psychosocial measures as dependent variables. The regression models were performed to better understand and predict the impact of sociodemographic factors on the psychosocial domains of participants.

Model 1 in Table 5 shows that education $(\mathrm{b}=0.84, \mathrm{p}=0.012)$ and marital status $(\mathrm{b}=0.77, \mathrm{p}=0.034)$ were associated with more symptoms of depression, while monthly income $(b=-1.89, p<0.001)$ was associated with fewer symptoms of depression. These demographic variables explained $31 \%$ of the GDS results, independent of other variables $\left(\mathrm{R}^{2}=0.31, \mathrm{~F}=1.895, p<0.01\right)$. The effect size was moderate for monthly income, family status, and education level $\left(\mathrm{f}^{2}=\right.$ 0.28 ).

Model 2 (see Table 6) demonstrates that monthly income $(b=2.36, p<$ $0.001)$, health status $(b=0.70, p=0.030)$, and church attendance $(b=1.64, p$ $=.053$ ) were all associated with greater subjective happiness (SHS), while education $(b=-1.009, p=0.006)$ was negatively associated with SHS. For overall

Table 5. Associations of Sociodemographic Factors with GDS-15.

\begin{tabular}{cccccccc}
\hline $\begin{array}{c}\text { Sociodemographic } \\
\text { Variables }\end{array}$ & $\mathrm{B}$ & $\mathrm{SE}$ & Beta & $\mathrm{t}$ & $\mathrm{p}$ & $\mathrm{R}^{2}$ & $\mathrm{~F}$ \\
\hline Model $1, p<0.01$ & & & & & & & \\
Monthly income & -1.89 & 0.37 & -0.60 & -5.22 & $<0.001$ & 0.31 & 1.895 \\
Marital status & 0.77 & 0.35 & 0.17 & 1.85 & 0.034 & & \\
Education level & 0.84 & 0.33 & 0.31 & 2.78 & 0.012 & & \\
\hline
\end{tabular}

Notes: GDS-15, Geriatric Depression Scale; SE, standard error.

Table 6. Associations of sociodemographic factors with SHS.

\begin{tabular}{|c|c|c|c|c|c|c|c|}
\hline $\begin{array}{c}\text { Sociodemographic } \\
\text { Variables }\end{array}$ & $\mathrm{B}$ & SE & Beta & $\mathrm{t}$ & $\mathrm{p}$ & $\mathrm{R}^{2}$ & $\mathrm{~F}$ \\
\hline \multicolumn{8}{|l|}{ Model 2, $p<0.001$} \\
\hline Education level & -1.09 & 0.38 & -0.29 & -2.84 & 0.006 & 0.44 & 4.502 \\
\hline Monthly income & 2.36 & 0.45 & 0.56 & 5.13 & $<0.001$ & & \\
\hline Church attendance & 1.65 & 0.84 & 0.17 & 1.96 & 0.053 & & \\
\hline Health status & 0.70 & 0.31 & 0.21 & 2.19 & 0.030 & & \\
\hline
\end{tabular}

Notes: SHS, Subjective Happiness Scale; SE, standard error. 
SHS, the explained variance of the sociodemographic factors was $44 \%\left(R^{2}=0.44\right.$, $\mathrm{F}=4.502, p<0.001)$.

Model 3 (see Table 7) indicates that church attendance $(b=3.56, p=0.001)$, monthly income $(b=3.65, p<0.001)$, and health status $(b=-1.43, p=0.001)$ were each significantly positively associated with SWLS score, while education ( $b$ $=-1.04, p=0.035)$ and sex (female) $(b=-1.93, p=0.032)$ showed significant negative associations with it. In this model the explained variance was $63 \%\left(\mathrm{R}^{2}=\right.$ $63 \%, \mathrm{~F}=4.728, p<0.001)$. The effect size $(\hat{f}=0.61)$ was large for sex, monthly income, church attendance, health condition, and education level.

Model 4 as presented in Table 8 indicates that monthly income $(\mathrm{b}=8.68, p<$ $0.001)$, church attendance $(\mathrm{b}=11.89, p<0.001)$, and health status $(\mathrm{b}=4.97, p<$ $0.001)$ were each positively associated with the participants' spiritual wellbeing (SWBS). Both being a woman $(\mathrm{b}=-6.40, p<0.001)$ and education $(\mathrm{b}=-3.57, \mathrm{p}$ $=0.025)$ were negatively associated with SWBS. The explained variance in this model was $58 \%\left(\mathrm{R}^{2}=58 \%, \mathrm{~F}=4.728, p<0.001\right)$. The effect sizes were large for sex, monthly income, church attendance, health condition, and education level $\left(f^{2}=0.57\right)$.

Moreover, as shown in Figure 1, multiple regression was also used to determine the associations between the four dependent psychosocial variables. Specifically, between SHS and SWLS, there was a weak, positive linear correlation,

Table 7. Associations of sociodemographic factors with SWLS.

\begin{tabular}{|c|c|c|c|c|c|c|c|}
\hline $\begin{array}{c}\text { Sociodemographic } \\
\text { Variables }\end{array}$ & $\mathrm{B}$ & SE & Beta & $\mathrm{t}$ & $\mathrm{p}$ & $\mathrm{R}^{2}$ & $\mathrm{~F}$ \\
\hline \multicolumn{8}{|l|}{ Model 3, $p<0.001$} \\
\hline Sex (Female) & -1.93 & 0.88 & -0.13 & -2.02 & 0.032 & 0.63 & 4.728 \\
\hline Monthly income & 3.65 & 0.58 & 0.56 & 6.34 & $<0.001$ & & \\
\hline Church attendance & 3.56 & 1.08 & 0.23 & 3.24 & $<0.001$ & & \\
\hline Health status & 1.43 & 0.40 & 0.28 & 3.63 & $<0.001$ & & \\
\hline Education level & -1.04 & 0.48 & -0.18 & -2.16 & 0.035 & & \\
\hline
\end{tabular}

Notes: SWLS, Satisfaction with Life Scale; SE, standard error.

Table 8. Associations of Sociodemographic Factors with SWBS.

\begin{tabular}{|c|c|c|c|c|c|c|c|}
\hline $\begin{array}{c}\text { Sociodemographic } \\
\text { Variables }\end{array}$ & $\mathrm{B}$ & SE & Beta & $\mathrm{t}$ & $\mathrm{P}$ & $\mathrm{R}^{2}$ & $\mathrm{~F}$ \\
\hline \multicolumn{8}{|l|}{ Model $4, p<0.001$} \\
\hline Sex (Female) & -6.40 & 2.83 & -0.16 & -2.30 & 0.027 & 0.58 & 4.728 \\
\hline Monthly income & 8.68 & 1.88 & 0.44 & 4.64 & $<0.001$ & & \\
\hline Church attendance & 11.89 & 3.42 & 0.27 & 3.48 & $<0.001$ & & \\
\hline Health status & 4.97 & 1.29 & 0.32 & 3.81 & $<0.001$ & & \\
\hline Education level & -3.57 & 1.56 & -0.21 & -2.34 & 0.025 & & \\
\hline
\end{tabular}

Notes: SWBS, Spiritual Wellbeing Scale; SE, standard error. 


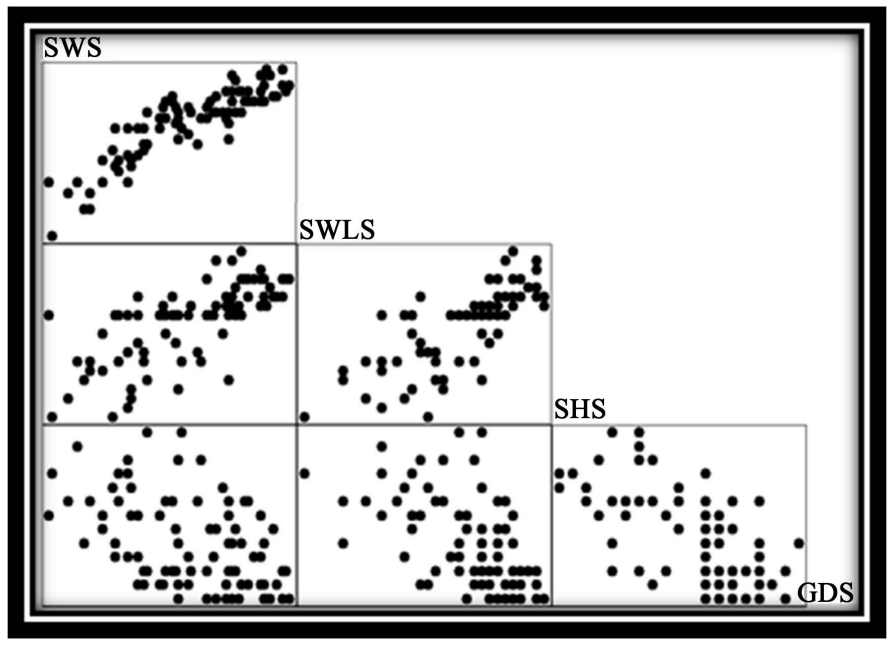

Figure 1. Associations between the four dependent psychometrical measures.

as there was a loose placing of points around the regression line, with $p<0.001$, $\mathrm{R}^{2}=0.059$, and $\mathrm{F}(1.87)=126.99$. In this way, for each point increase in the SHS, SWLS also increased by 1.22 points. In addition, there was a strong, positive, linear correlation between SHS and SWBS, with $p<0.001, \mathrm{R}^{2}=0.49$, and $\mathrm{F}(1,87)$ $=86.12$, and the points seemed to be concentrated narrowly around the regression line. For each point increase in SHS, SWBS also increased by 3.33 points. Finally, between SWLS and SWS, there was a very strong, positive, linear correlation, with $p<0.001, \mathrm{R}^{2}=0.76$, and $\mathrm{F}(1,87)=290.02$, meaning a very dense concentration of points around the regression line. For each unit increase in SWS, SWLS increased by 0.29 points. GDS- 15 was not correlated significantly with any other test score (SWLS, SHS, or SWBS).

\section{Discussion}

There is limited knowledge about how demographic and socioeconomic predictors contribute to individual-level wellbeing among older people in Greece and other European countries. Thus, the present study aimed to investigate the wellbeing of community-dwelling Greek older adults by examining the associations of a range of background factors, including gender, age, marital status, education level, religious involvement, monthly income, and perceived health status, with the wellbeing domains of GDS-15, SHS, SWLS, and SWBS.

The findings of this study suggest that the respondents were fairly satisfied with their lives, had above average emotional state and spiritual wellbeing, and enjoy their lives, although they had lower income compared to the general older population in the EU (Hellenic Statistical Authority, 2019b). From a developmental psychology perspective, this finding provides evidence for socioemotional selectivity theory, which suggests that individuals' wellbeing improves with advancing age, as older people tend to focus on more emotionally positive experiences (Carstensen et al., 2003). Furthermore, studies of late-life wellbeing also indicate that contrary to negative stereotypes, older adults often enjoy high de- 
grees of life satisfaction, at least in part because they tend to be healthier and remain more active in more domains than may have been the case for previous generations (Navarro-Prados, Serrate-Gonzalez, Munoz Rodriguez, \& Diaz-Orueta, 2017; Versey \& Newton, 2013). Various studies have reported low rates of depression among Greek older adults and better-than-average emotional states compared to those from other Mediterranean and Southern-eastern European countries, which may contribute to better subjective happiness and wellbeing (Castro-Costa et al., 2007; Eurostat, 2018; Foscolou et al., 2016; Kok, Avendano, Bago d'Uva, \& Mackenbach, 2012). However, other studies conducted in Greece during the period of financial austerity have found a significant increase in depressive symptoms, suggesting that old age, low income, and poor access to social and health care services and also female gender are risk factors for depression and other mental health issues (Carayanni, Stylianopoulou, Koulierakis, Babatsikou, \& Koutis, 2012; Economou et al., 2013).

Correlational results in this study showed a significant association among the three positive psychosocial measures (SHS, SWLS, and SWBS), while depression (GDS-15) was not associated with any of these factors. The significant associations between happiness, life satisfaction, and wellbeing reflect current perspectives linking these factors (Veenhoven, 2010).

The bivariate associations revealed that higher income was related to higher wellbeing on all four domains of wellbeing, while higher educational attainment was related to worse outcomes on all domains. Attending church and being in better health were associated with higher scores on the remaining three domains of wellbeing (life satisfaction, happiness, and spiritual wellbeing). Women experienced lower satisfaction with life and spiritual wellbeing than men did. Regarding marital status, being married or cohabiting was associated with lower scores for depression. Although the existing literature also highlights how age relates to wellbeing (Staptoe, Deaton, \& Stone, 2015), our findings showed that age was not significantly associated with any domain of wellbeing.

The main analyses showed that these predictors together explained a significant part of the variance in scores on all the psychosocial domains, at $31 \%$ for GDS-15, 44\% for SHS, $63 \%$ for SWLS, and 58\% for SWBS. Our results confirmed that higher monthly income was related to better outcomes on all psychosocial outcome measures. This finding substantiates the anticipated close relationship between psychological wellbeing and poverty, consistent with the findings of previous studies (Arendt, 2005; Camfield \& Esposito, 2014; Yu \& Chen, 2016), indicating that higher income could help people overcome difficult circumstances including hunger and cold that may negatively affect their subjective wellbeing. Moreover, money leads to increased happiness if it can be exchanged for goods that will improve an individual's utility and general social rank (Boyce, Brown, \& Moore, 2010). Income, according to Easterlin (1974, 1995), influences wellbeing not only because it enables an individual to satisfy their own and their family's needs but also because relative income has a social comparison function; that is, individuals may judge their own success or their 
worth in the community by their social status based on their relative wealth.

The present results also suggest that self-rated health is an important determinant of multiple elements of positive wellbeing. Previous studies have found that subjective and/or self-related health tend to be closely associated with measures of individual wellbeing (Staptoe et al., 2015), although this hypothesis has not been fully tested and there is no consensus on what process can explain this relationship (Monden, 2014; Ngamaba, Panagioti, \& Armitage, 2017). Maintaining good health increases the capacity of an older person to live independently, conduct activities of daily living, and perform other personal care activities and household work, which entail autonomy, reflected in the older person's psychological wellbeing (Celik, Celik, Hikmet, \& Khan, 2017). At the same time, it is important to emphasize that this relationship is reciprocal; not only does health affect wellbeing, but wellbeing and happiness also influence physical functioning and longevity among healthy populations, indicating that happiness might be a protective factor against illness (Veenhoven, 2007). Individuals who feel happy can better attain resources to create healthier living conditions and habits, including active engagement in physical activity and health behaviors (Delle Fave et al., 2018; Diener \& Seligman, 2004). Moreover, such individuals are better prepared to respond to health problems and manage health issues more effectively (Schimmel, 2009).

Previous studies, especially those by social scientists, of the association between education level and psychosocial wellbeing in adulthood have reported mixed findings (Blanchflower \& Oswald, 2004; Powdthhavee, Lekfuangfu, \& Wooden, 2015), either a negative effect (Shields, Wheatley-Price, \& Wooden, 2009) or a statistically non-significant effect (Von Humboldt et al., 2015) of education on overall life satisfaction, happiness, and spiritual wellbeing. Our results confirmed that higher education level is associated with more depressive symptoms as well as lower scores on the SHS, SWLS, and SWBS. This finding may seem paradoxical, in that higher education is generally associated with a range of positive outcomes, particularly in lower-income countries (Diener, Sandvik, Seidlitz, \& Diener, 1993; Veenhoven, 1994). However, for this particular sample, this finding may be attributed to the fact that those with low income, relative to their level of education, may experience disappointment due to negative social comparison effects, which may contribute to lower wellbeing. Other possible reasons for the negative association between more education and lower wellbeing reported in the present study may be explained by a previous finding that more education may increase stress levels (Powdthhavee et al., 2015), which may, in turn, increase individuals' tendency to over-commit to work in order to attain higher position and earn better income. Surprisingly, schooling may also be negatively related to wellbeing if individuals have unrealistic expectations that cannot be met, thus increasing their goal-achievement gap. Furthermore, over-education may decrease an individual's preference for developing close romantic relationships and raising children (Isen \& Stevenson, 2010), which are well-known predictors of life satisfaction and wellbeing. 
Female gender was negatively associated with life satisfaction and spiritual wellbeing. This finding is consistent with a significant body of research on gender differences in wellbeing in late life, which has generally reported that women experience more deterioration in wellbeing and mental health outcomes than do men in older adulthood (Carmel \& Bernstein, 2003; Luppa et al., 2012), and that this gap continues to widen throughout the course of late life (Diener, Eunkook, Lucas, \& Smith, 1999). A study by Carmel (2019) found that women in late life tend to have generally lower scores on indicators of wellbeing and coping resources than do men, and that women present more symptoms of distress, loneliness, and disability than do men. Some reasons that may account for at least some of this gender disparity may be the fact that older women are more likely to take on stressful family caregiving roles compared to older men (Marks, Lambert, \& Choi, 2002) and are more likely to be widowed than men (Pinquart \& Sörensen, 2001). However, these disparities may be partly ameliorated by the fact that women also tend to be more involved in social support networks including extended family and religious communities (Francis \& Penny, 2014; McLaughlin, Vagenas, Pachana, Begum, \& Dobson, 2010). It is worth noting that female gender was not associated with emotional state on GDS-15 or subjective happiness on SHS. In general, women have been found to be more prone to symptoms of depression than are men (Parker \& Brotchie, 2010; Piccinelli \& Wilkinson, 2000), but there are also considerable cross-cultural variations in the extent of these differences (Salk, Hyde, \& Abramson, 2017; Van de Velde, Bracke, Levecque, \& Meuleman, 2010).

Church attendance was found to be significantly associated with better subjective happiness, life satisfaction, and spiritual wellbeing after controlling for other sociodemographic variables such as gender, income, education level, and health. There is substantial literature documenting the positive relationship between religious engagement (e.g. church attendance) and subjective wellbeing (Diener et al., 1999; Gartner, Larson, \& Allen, 1991; Krause, 2011), particularly in old age (Krause \& Hayward, 2016; Boey, 2003). Consistent with previous studies, religious engagement was found to have a positive impact both on the induction of positive emotions and on satisfaction with life, both among churchgoers per se and in terms of the spirituality domain of wellbeing, which fosters a greater sense of coherence and meaning in life (Villani, Sorgente, Iannello, \& Antonietti, 2019; Von Humboldt et al., 2015). A study by Ellison (1991) has found that religious individuals with strong faith have higher levels of wellbeing, greater subjective happiness, and better psychosocial adjustment after stressful life events. Religious participation may contribute to wellbeing in a number of ways; in particular, church participation provides connection to a strong social support system that can buffer the impact of a negative life event (Krause, Ellison, Shaw, Marcum, \& Boardman, 2001). It also helps with the development and application of an array of psychological coping mechanisms (Pargament, Koenig, Tarakeshwar, \& Hahn, 2004), for example providing a sense of meaning and purpose (Galek, Flannelly, Ellison, Silton, \& Jankowski, 2015) that can be especially 
helpful in dealing with the challenges associated with aging (Krause, 2003).

Finally, contrary to expectations, being married was associated with lower depressive symptoms but was unrelated to other psychosocial outcomes examined in the present study. These findings are not in keeping with those of several previous studies, which have shown that marriage is a significant determinant of subjective wellbeing (Mastekaasa, 1994; Veenhoven, 2010; Verbakel, 2012). However, a growing body of literature points out that that the advantages of marriage for life satisfaction declined between 1981 and 2009, particularly among men, in both developed and developing countries (Mikucka, 2016), suggesting that being married does not contribute to wellbeing in adulthood (Glenn \& Weaver, 1988; Ryan, Hugites, \& Hawdon, 1998; DePaulo \& Morris, 2005). A study by Shapiro and Kayes (2008) examined perceived social wellbeing among individuals by marital history (e.g. married, single, cohabiting, divorced) and found no evidence to suggest that being single is linked to lower perceived social wellbeing or that being married has an advantage over not being married with respect to wellbeing. In addition, Akiyama Antonucci, Takahashi, and Langfahl (2003) suggest that compared to having a family, having close friends and relatives may have a greater positive effect on wellbeing especially among older people. From the perspective of developmental psychology, it can be speculated that for the present study sample, living with a vertical family was not unequivocally associated with harmonious relationships, given that changes over time in spouses' relationship quality may vary by crucial factors such as individual developmental stage, type of relationship, and personality traits. Furthermore, there might be cultural factors related to the specific experiences of Greek older adults that might explain the contrast between the findings of the present study and those of previous studies. Longitudinal studies are needed to explore long-term causal or selective effects of marital status on wellbeing.

\section{Limitations and Future Research}

The limitations of this study include the use of a relatively small convenience sample drawn from a single metropolitan area. Self-selection effects may have biased the sample towards happier and healthier individuals, as those with more mental and physical health problems may have been less likely to volunteer or to complete the study. Among the old-old group, cognitive limitations may have exacerbated this effect. There may also be important differences between older adults living in Athens and those living in rural areas or in other urban areas of Greece; therefore, caution should be exercised when generalizing the findings of the study to the older population across the country. Additionally, the study's cross-sectional design precludes inferences about causal or directional relationships, given that wellbeing changes over time. Future studies should thus extend the present insights by expanding the sample to include a larger number of older adults randomly selected from a wider cross-section of urban and rural areas within Greece; moreover, expanding the design to examine the effects longitudinally would help draw causal inferences. Further, future studies should include 
information on functional status, medication, and disability, because this could provide a deeper understanding of the aging process. Last, the use of self-report measures is an important limitation of the present study, because various biases may affect the results, including response bias and social desirability bias among the respondents. This study also highlights the need for future research on the oldest-old to separately investigate wellbeing indicators in this group, and future research should also capture a religion-specific perspective, considering the impact of religious involvement in the shaping of wellbeing in late life.

\section{Conclusion}

From the life course perspective, the present study suggests that old age brings about developmental, economic, and social challenges and provides a better understanding of the wellbeing indicators that influence successful aging among this population. Specifically, the findings of the present study revealed that psychosocial domains of wellbeing in a selected group of elderly Greek people were affected by a number of social, health, and economic factors. In addition to the intrinsic benefits of psychosocial wellbeing, these dimensions affect quality of life at an international level by influencing other critical outcomes related to morbidity, disability, and mortality. Dealing with these challenges is important not only for individuals but also for their families and social systems that are responsible for providing support and care for the older adult population, particular for those with low socioeconomic status. In this light, it is crucial for policymakers and mental health professionals to recognize the important role of socio-demographic factors for the wellbeing of community-dwelling older adults and integrate attention to these factors in order to develop preventive programs focusing on older adults' health care and psychosocial needs to reduce the burden of poverty, illness and disability and increase positive life outcomes.

\section{Acknowledgements}

This study was supported by the Aging Department of the Greek Association of Mental Health for Children and Adults (Project Number 3826/09.2018). I would also like to thank all the participants, because without their generous support, this study would not have been possible.

\section{Conflicts of Interest}

The author reports no conflicts of interest relevant to this work.

\section{References}

Akiyama, H., Antonucci, T., Takahashi, K., \& Langfahl, E. S. (2003). Negative Interactions in Close Relationships across the Life Span. Journals of Gerontology: Psychological Sciences and Social Sciences, 58, 70-79. https://doi.org/10.1093/geronb/58.2.P70

Arendt, J. N. (2005). Income and "Outcomes" for Elderly: Do the Poor Have a Poorer Life? Social Indicators Research, 70, 327-347.

https://doi.org/10.1007/s11205-004-1545-8 
Avgoustaki, A., Dimitriadou, D., \& Stalikas, A. (2012). The Subjective Happiness Scale (SHS). In A. Stalikas, S. Triliva, \& P. Roussi (Eds.), Psychometric Instruments in Greece (2nd ed., pp. 1753-1765). Athens, Greece: Pedio.

Baek, M. J., Kim, K., Park, Y. H., \& Kim, S. Y. (2016). The Validity and Reliability of the Mini-Mental State Examination-2 for Detecting Mild Cognitive Impairment and Alzheimer's Disease in a Korean Population. PLoS ONE, 11, e0163792.

https://doi.org/10.1371/journal.pone.0163792

Beaton, D. E., Bombardier, C., Guillemin, F., \& Ferraz, M. B. (2000) Guidelines for the Process of Cross-Cultural Adaptation of Self-Report Measures. Spine, 259, 3186-3191. https://doi.org/10.1097/00007632-200012150-00014

Blanchflower, D., \& Oswald, A. J. (2004). Well-Being over Time in Britain and the USA. Journal of Public Economics, 88, 1359-1386. https://doi.org/10.1016/S0047-2727(02)00168-8

Boey, K. W. (2003). Religiosity and Psychological Well-Being of Older Women in Hong-Hong. International Journal of Psychiatric Nursing Research, 8, 921-935.

Boyce, C. J., Brown, G. D., \& Moore, S. C. (2010). Money and Happiness: Rank of Income, Not Income, Affects Life Satisfaction. Psychological Science, 21, 471-475. https://doi.org/10.1177/0956797610362671

Bufford, R. K., Paloutzian, R. F., \& Ellison, C. W. (1991). The Spiritual Well-Being Scale. Journal of Psychology \& Theology, 19, 56-70. https://doi.org/10.1177/009164719101900106

Camfield, L., \& Esposito, L. (2014). A Cross-Country Analysis of Perceived Economic Status and Life Satisfaction in High- and Low-Income Countries. World Development, 59, 212-223. https://doi.org/10.1016/j.worlddev.2014.01.018

Carayanni, V., Stylianopoulou, C., Koulierakis, G., Babatsikou, F., \& Koutis, C. (2012). Sex Differences in Depression among Older Adults: Are Older Women More Vulnerable than Men in Social Risk Factors? The Case of Open Care Centers for Older People in Greece. European Journal of Ageing, 9, 177-186.

https://doi.org/10.1007/s10433-012-0216-x

Carmel, S. (2019). Health and Well-Being in Late Life: Gender Differences Worldwide. Frontiers in Medicine, 6, 218. https://doi.org/10.3389/fmed.2019.00218

Carmel, S., \& Bernstein, J. (2003). Gender Differences in Physical Health and Psychosocial Well-Being among Four Age Groups of Elderly People in Israel. International Journal of Aging and Human Development, 56, 113-131. https://doi.org/10.2190/87YH-45QN-48TY-9HN8

Carstensen, L. L., Fung, H. H., \& Charles, S. T. (2003). Socioemotional Selectivity Theory and the Regulation of Emotion in the Second Half of Life. Motivation and Emotion, 27, 103-123. https://doi.org/10.1023/A:1024569803230

Castro-Costa, E., Dewey, M., Stewart, S., Banerjee, F., Huppert, C., Mendonca-Lima, C. et al. (2007). Prevalence of Depressive Symptoms and Syndromes in Later Life in Ten European Countries: The SHARE Study. British Journal of Psychiatry, 191, 393-401. https://doi.org/10.1192/bjp.bp.107.036772

Celik, S. S., Celik, Y., Hikmet, N., \& Khan, M. M. (2017). Factors Affecting Life Satisfaction of Older Adults in Turkey. The International Journal of Aging and Human Development, 87, 392-414. https://doi.org/10.1177/0091415017740677

Creavin, S. T., Wisniewski, S., Noel-Storr, A. H., Trevelyan, C. M., Hampton, T., Rayment, D. et al. (2016). Mini Mental State Examination (MMSE) for the Detection of Dementia in Clinically Unevaluated People Aged 65 and over in Community and Primary Care Populations. Cochrane Database System Review, 13, CD0111145. 
https://doi.org/10.1002/14651858.CD011145.pub2

Delle Fave, A., Bassi, M., Boccaleti, E. S., Roncaglione, C., Bernardelli, G., \& Mari, D. (2018). Promoting Well-Being in Old Age: The Psychological Benefits of Two Training Programs of Adapted Physical Activity. Frontiers in Psychology, 9, 828. https://doi.org/10.3389/fpsyg.2018.00828

DePaulo, B. M., \& Morris, W. L. (2005). Singles in Society and in Science. Psychological Inquiry, 16, 57-83. https://doi.org/10.1207/s15327965pli162\&3_01

Diener, E. D. Sandvik, E., Seidlitz, L., \& Diener, M. (1993). The Relationship between Income and Subjective Well-Being: Relative or Absolute? Social Indicators Research, 28, 195-223. https://doi.org/10.1007/BF01079018

Diener, E. D., \& Seligman, M. E. P. (2004). Beyond Money: Toward an Economy of Well-Being. Psychological Science in the Public Interest, 5, 1-31. https://doi.org/10.1111/j.0963-7214.2004.00501001.x

Diener, E. D., Diener, M., \& Diener, C. (2009). Factors Predicting the Subjective Well-Being of Nations. In E. Diener (Ed.), Social Indicators Research Series (Vol. 38, pp. 43-70). Dordrecht, The Netherlands: Springer.

https://doi.org/10.1007/978-90-481-2352-0_3

Diener, E. D., Emmons, R. A., Larsen, R. J., \& Griffin, S. (1985). The Satisfaction with Life Scale. Journal of Personality Assessment, 49, 71-75. https://doi.org/10.1207/s15327752jpa4901_13

Diener, E. D., Eunkook, M., Lucas, R. E., \& Smith, H. L. (1999). Subjective Well-Being: Three Decades of Progress. Psychological Bulletin, 125, 276-302. https://doi.org/10.1037/0033-2909.125.2.276

Easterlin, R. (1974). Does Economic Growth Improve the Human Lot? Some Empirical Evidence. In R. David, \& R. Reder (Eds.), Nations and Households in Economic Growth: Essays in Honor of Moses Abramovitz (pp. 89-125). New York: Academic Press. https://doi.org/10.1016/B978-0-12-205050-3.50008-7

Easterlin, R. (1995). Will Raising the Incomes of All Increase the Happiness of All? Journal of Economic Behavior and Organization, 27, 35-47. https://doi.org/10.1016/0167-2681(95)00003-B

Economou, M., Madianos, M., Peppou, L. E., Patelakis, A., \& Stefanis, C. N. (2013). Major Depression in the Era of Economic Crisis: A Replication of a Cross-Sectional Study across Greece. Journal of Affective Disorders, 145, 308-314. https://doi.org/10.1016/j.jad.2012.08.008

Efklides, A., Kalaitzidou, M., \& Chankin, G. (2003). Subjective Quality of Life in Old Age in Greece: The Effect of Demographic Factors, Emotional State, and Adaptation to Aging. European Psychologist, 8, 178-191. https://doi.org/10.1027//1016-9040.8.3.178

Ellison, C. W. (1991). Religious Involvement and Subjective Well-Being. Journal of Health and Social Behavior, 32, 80-89. https://doi.org/10.2307/2136801

European Commission, Economic and Financial Affairs (2018). The 2018 Ageing Report: Economic and budgetary projections for the 28 EU Member States (2016-2070). Institutional Paper No. 079, Brussels, Belgium: European Commission.

Eurostat (2015). People in the EU: Who Are We and How Do We Live? https://ec.europa.eu/eurostat/documents/3217494/7089681/KS-04-15-567-EN-N.pdf

Eurostat (2018). Mental Health and Related Issues Statistics. https://ec.europa.eu/eurostat/statistics-explained/index.php/Mental_health_and_relate d_issues_statistics\#Extent_of_depressive_disorders

Folstein, M. F., Folstein, S. E., \& McHugh, P. R. (1975). “Mini-Mental State”: A Practical 
Method for Grading the Cognitive State of Patients for the Clinician. Journal of Psychiatric Research, 12, 189-198. https://doi.org/10.1016/0022-3956(75)90026-6

Foscolou, A., Polychronopoulos, E., Paka, E., Tyrovolas, S., Bountziouka, V., Zeimbekis, A. et al. (2016). Lifestyle and Health Determinants of Cardiovasze within the MEDIS Study. Hellenic Journal of Cardiology, 57, 407-414. https://doi.org/10.1016/j.hjc.2016.11.021

Foscolou, A., Tyrovolas, S., Soulis, G., Mariolis, A., Piscopo, S., Valacchi, G. et al. (2017). The Impact of the Financial Crisis on Lifestyle Health Determinants among Older Adults Living in the Mediterranean Region: The Multinational MEDIS Study (2005-2015). Journal of Preventive Medicine and Public Health, 50, 1-9. https://doi.org/10.3961/jpmph.16.101

Fountoulakis, C., Tsolaki, M., \& Iakovides, A. (1999). The Validation of the Short Form of Geriatric Depression Scale (GDS) in Greece. Aging, 11, 367-372. https://doi.org/10.1007/BF03339814

Fountoulakis, C., Tsolaki, M., Chantzi, E., \& Kazis, A. (2000). Mini Mental State Examination. A Validation Study in Demented Patients from the Elderly Greek Population. American Journal of Alzheimer's Diseases, 15, 342-347.

Francis, L. J., \& Penny, G. (2014). Gender Differences in Religion. In V. Saroglou (Ed.), Religion, Personality, and Social Behavior (pp. 313-337). New York: Psychology Press.

Frijters, P., \& Beaton, T. (2008). The Mystery of U-Shaped Relationship between Happiness and Age. Journal of Economic Behavior \& Organization, 82, 525-542. https://doi.org/10.1016/j.jebo.2012.03.008

Galek, K., Flannelly, K. J., Ellison, C. G., Silton, N. R., \& Jankowski, K. R. (2015). Religion, Meaning and Purpose, and Mental Health. Psychology of Religion and Spirituality, 7, 1-12. https://doi.org/10.1037/a0037887

Gartner, J., Larson, D., \& Allen, G. D. (1991). Religious Commitment and Mental Health: A Review of the Empirical Literature. Journal of Psychology and Theology, 19, 6-25. https://doi.org/10.1177/009164719101900102

George, L. K. (2010). Still Happy after All These Years: Research Frontiers on Subjective Well-Being in Later Life. The Journals of Gerontology Series B: Psychological Sciences and Social Sciences, 65B, 331-339. https://doi.org/10.1093/geronb/gbq006

Glenn, N. D., \& Weaver, C. N. (1988). The Changing Relationship of Marital Status to Reported Happiness. Journal of Marriage and the Family, 50, 317-324. https://doi.org/10.2307/351999

Gobbens, R. J. J., \& Remmen, R. (2019). The Effects of Sociodemographic Factors on Quality of Life among People Aged 50 Years or Older Are Not Unequivocal: Comparing SF-12, WHOOL-BREF, and WHOOL-OLD. Clinical Interventions in Aging, 14, 231-239. https://doi.org/10.2147/CIA.S189560

Gwozdz, W., \& Sousa-Poza, A. (2010). Ageing, Health and Life-Satisfaction of the Oldest Old: An Analysis for Germany. Social Indicators Research, 97, 397-417. https://doi.org/10.1007/s11205-009-9508-8

Hagerty, M. R., \& Veenhoven, R. (2003). Wealth and Happiness Revisited: Growing Wealth of Nations Does Go with Greater Happiness. Social Indicator Research, 64, 1-27. https://doi.org/10.1023/A:1024790530822

Hayward, R. D., \& Elliott, M. (2014). Cross-National Analysis of the Influence of Cultural Norms and Government Restrictions on the Relationship between Religion and Well-Being. Review of Religious Research, 56, 23-43.

https://doi.org/10.1007/s13644-013-0135-0 
Hellenic Statistical Authority (2019a). Greece in Figures.

https://www.statistics.gr/el/greece-in-figures

Hellenic Statistical Authority (2019b). Living Conditions in Greece. http://www.statistics.gr/documents/20181/14479704/LivingConditionsInGreece_0519. pdf/e74da3b7-4d60-4c91-a59b-e73749c259ca

Isen, A., \& Stevenson, B. (2010). Women's Education and Family Behavior: Trends in Marriage, Divorce and Fertility. NBER Working Paper Series No. 15725, Cambridge, MA: National Bureau of Economic Research. https://doi.org/10.3386/w15725

Jivraj, S., Nazroo, J., Vanhoutte, B., \& Chandola, T. (2014). Aging and Subjective Well-Being in Later Life. The Journals of Gerontology Series B: Psychological Sciences and Social Sciences, 69, 930-941. https://doi.org/10.1093/geronb/gbu006

Kafetsios, K., \& Sideridis, G. D. (2006). Attachment, Social Support and Well-Being in Young and Older Adults. Journal of Health Psychology, 11, 863-876. https://doi.org/10.1177/1359105306069084

Kalogeraki, S. (2009). The Divergence Hypothesis in Modernization Theory across Three European Countries: The UK, Sweden and Greece. Cultural Unbound: Journal of Current Cultural Research, 1, 161-178. https://doi.org/10.3384/cu.2000.1525.09110161

Kinsella, K., \& Velkoff, V. A. (2001). An Aging World. Washington DC: US Census Bureau. https://doi.org/10.1037/e407472005-001

Kok, R., Avendano, M., Bago d’Uva, T., \& Mackenbach, J. (2012). Can Reporting Heterogeneity Explain Differences in Depressive Symptoms across Europe? Social Indicators Research, 105, 191-210. https://doi.org/10.1007/s11205-011-9877-7

Koutsampelas, C. (2012). Aspects of Elderly Poverty in Cyprus. Cyprus Economy Policy Review, 6, 69-89.

Krause, N. (2003). Religious Meaning and Subjective Well-Being in Late Life. The Journals of Gerontology Series B: Psychological Sciences and Social Sciences, 58, S160-S170. https://doi.org/10.1093/geronb/58.3.S160

Krause, N. (2011). Religion and Health: Making Sense of a Disheveled Literature. Journal of Religion and Health, 50, 20-35. https://doi.org/10.1007/s10943-010-9373-4

Krause, N., \& Hayward, R. D. (2016). Religion, Health, and Aging. In L. K. George, \& K. F. Ferraro (Eds.), Handbook of Aging and the Social Sciences (pp. 251-270). San Diego, CA: Academic Press. https://doi.org/10.1016/B978-0-12-417235-7.00012-3

Krause, N., Ellison, C. G., Shaw, B. A., Marcum, J. P., \& Boardman, J. D. (2001). Church-Based Social Support and Religious Coping. Journal for the Scientific Study of Religion, 40, 637-656. https://doi.org/10.1111/0021-8294.00082

Luppa, M., Sikorski, C., Luck, T., Ehreke, L., Konnopka, A., Wise, B. et al. (2012). Ageand Gender-Specific Prevalence of Depression in Latest Life-Systematic Review and Meta-Analysis. Journal of Affective Disorders, 136, 212-221. https://doi.org/10.1016/j.jad.2010.11.033

Lutz, W., O'Neill, B. C., \& Scherbov, S. (2003). Europe's Population at a Turning Point. Science, 299, 1991-1992. https://doi.org/10.1126/science.1080316

Lyrakos, G. N., Xatziagelaki, A. K., Papazofiropoulou, A. K., Batistaki, C., Damigos, D., Mathianakis, G. et al. (2013). Translation and Validation Study of the Satisfaction with Life Scale (SWLS) in Greek General Population, Diabetes Mellitus and Patients with Emotional Disorders. European Psychiatry, 28, 1. https://doi.org/10.1016/S0924-9338(13)76471-X

Lyubomirsky, S., \& Lepper, H. S. (1999). A Measure of Subjective Happiness: Preliminary Reliability and Construct Validation. Social Indicators Research, 46, 137-155. 
https://doi.org/10.1023/A:1006824100041

Marks, N. F., Lambert, J. D., \& Choi, H. (2002). Transitions to Caregiving, Gender, and Psychological Well-Being: A Prospective U.S. National Study. Journal of Marriage and Family, 64, 657-667. https://doi.org/10.1111/j.1741-3737.2002.00657.x

Mastekaasa, A. (1994). Psychological Well-Being and Marital Dissolution: Selection Effects? Journal of Family Issues, 15, 208-229. https://doi.org/10.1177/0192513X94015002004

McLaughlin, D., Vagenas, D., Pachana, N. A., Begum, N., \& Dobson, A. (2010). Gender Differences in Social Network Size and Satisfaction in Adults in Their 70s. Journal of Health Psychology, 15, 671-679. https://doi.org/10.1177/1359105310368177

Mikucka, M. (2016). The Life Satisfaction Advantage of Being Married and Gender Specialization. Journal of Marriage and Family, 78, 759-779. https://doi.org/10.1111/jomf.12290

Monden, C. (2014). Subjective Health and Subjective Well-Being. In A. C. Michalos (Ed.), Encyclopedia of Quality of Life and Well-Being Research (pp. 6423-6426). Dordrecht, Germany: Springer. https://doi.org/10.1007/978-94-007-0753-5_3957

Navarro-Prados, A. B., Serrate-Gonzalez, S., Munoz Rodriguez, J., \& Diaz-Orueta, U. (2017). Relationship between Personality Traits, Generativity, and Life Satisfaction in Individuals Attending University Programs for Seniors. The International Journal of Aging and Human Development, 87, 184-200.

https://doi.org/10.1177/0091415017740678

Ngamaba, K. H., Panagioti, M., \& Armitage, C. J. (2017). How Strongly Related Are Health Status and Subjective Well-Being? Systemic Review and Meta-Analysis. European Journal of Public Health, 27, 879-885. https://doi.org/10.1093/eurpub/ckx081

Oishi, S., Diener, E. F., Lucas, R. E., \& Suh, E. M. (1999).Cross-Cultural Variations in Predictors of Life-Satisfaction: Perspectives from Needs and Values. Personality and Social Psychology Bulletin, 25, 980-990. https://doi.org/10.1177/01461672992511006

Pargament, K. I., Koenig, H. G., Tarakeshwar, N., \& Hahn, J. (2004). Religious Coping Methods as Predictors of Psychological, Physical and Spiritual Outcomes among Medically Ill Elderly Patients: A Two-Year Longitudinal Study. Journal of Health Psychology, 9, 713-730. https://doi.org/10.1177/1359105304045366

Parker, G., \& Brotchie, H. (2010). Gender Differences in Depression. International Review of Psychiatry, 22, 429-436. https://doi.org/10.3109/09540261.2010.492391

Piccinelli, M., \& Wilkinson, G. (2000). Gender Differences in Depression. British Journal of Psychiatry, 177, 486-492. https://doi.org/10.1192/bjp.177.6.486

Pinquart, M., \& Sörensen, S. (2001). Gender Differences in Self-Concept and Psychological Well-Being in Old Age: A Meta-Analysis. The Journals of Gerontology: Series B, 56, 195-213. https://doi.org/10.1093/geronb/56.4.P195

Powdthhavee, N., Lekfuangfu, W., \& Wooden, M. (2015). What's the Good of Education on Our Overall Quality of Life? A Simultaneous Equation Model of Education and Life Satisfaction for Australia. Journal of Behavioral and Experimental Economics, 54, 10-21. https://doi.org/10.1016/j.socec.2014.11.002

Ryan, J., Hugites, M., \& Hawdon, J. (1998). Marital Status, General Life Satisfaction and the Welfare State: A Cross-National Comparison. International Journal of Comparative Sociology, 39, 224-237. https://doi.org/10.1177/002071529803900205

Salk, R. H., Hyde, J. S., \& Abramson, L. Y. (2017). Gender Differences in Depression in Representative National Samples: Meta-Analyses of Diagnoses and Symptoms. Psychological Bulletin, 143, 783-822. https://doi.org/10.1037/bul0000102 
Schimmel, J. (2009). Development as Happiness: The Subjective Perception of Happiness and UNDP's Analysis of Poverty, Wealth and Development. Journal of Happiness Studies, 10, 93-111. https://doi.org/10.1007/s10902-007-9063-4

Shapiro, A., \& Kayes, C. L. M. (2008). Marital Status and Social Well-Being: Are the Married Always Better Off? Social Indicators Research, 88, 329-346. https://doi.org/10.1007/s11205-007-9194-3

Sheikh, J. I., \& Yesavage, J. A. (1986). Geriatric Depression Scale (GDS): Recent Evidence and Development of a Shorter Version. Clinical Gerontologist: The Journal of Aging and Mental Health, 5, 165-173. https://doi.org/10.1300/J018v05n01_09

Shields, M. A., Wheatley-Price, S., \& Wooden, M. (2009). Life Satisfaction and the Economic and Social Characteristics of Neighborhoods. Journal of Population Economics, 22, 42-443. https://doi.org/10.1007/s00148-007-0146-7

Staptoe, A., Deaton, A., \& Stone, A. A. (2015). Psychological Wellbeing, Health and Ageing. The Lancet, 385, 640-648. https://doi.org/10.1016/S0140-6736(13)61489-0

Thøgersen-Ntoumani, C., Barboukis, V., Grano, C., Lucidi, F., Lindwall, M., Liukkonen, J. et al. (2011). Health and Well-Being Profiles of Older European Adults. European Journal of Aging, 8, 75-85. https://doi.org/10.1007/s10433-011-0186-4

Tombaugh, T. N., \& McIntyre, M. A. (1992). The Mini-Mental State Examination: A Comprehensive Review. Journal of the American Geriatrics Society, 40, 922-929. https://doi.org/10.1111/j.1532-5415.1992.tb01992.x

United Nations, Department of Economic and Social Affairs, Population Division (2017). World Population Prospects: The 2017 Revision, Key Findings and Advance Tables. Working Paper No. ESA/P/WP/248, New York: United Nations.

Van de Velde, S., Bracke, P., Levecque, K., \& Meuleman, B. (2010). Gender Differences in Depression in 25 European Countries after Eliminating Measurement Bias in the CES-D 8. Social Science Research, 39, 396-404.

https://doi.org/10.1016/j.ssresearch.2010.01.002

Veenhoven, R (2007). Trend Average Happiness in Nations 1946-2006: How Much People Like the Life They Live. World Database of Happiness, Trend Report, 2007-1. http://www.worlddatabaseofhappiness.eur.nl/hap_nat/nat_fp.htm

Veenhoven, R. (1994). Correlates of Happiness: 7,836 Findings from 603 Studies in 69 Nations 1911-1994. Rotterdam, The Netherlands: Erasmus University.

Veenhoven, R. (2010). Greater Happiness for a Greater Number. Journal of Happiness Studies, 11, 605-629. https://doi.org/10.1007/s10902-010-9204-Z

Verbakel, E. (2012). Subjective Well-Being by Partnership Status and Its Dependence on the Normative Climate. European Journal of Population/Revue Européenne de Démographie, 28, 205-232. https://doi.org/10.1007/s10680-012-9257-2

Versey, H. S., \& Newton, N. J. (2013). Generativity and Productive Pursuits: Pathways to Successful Aging in Late Midlife African American and White Women. Journal of Adult Development, 20, 185-196. https://doi.org/10.1007/s10804-013-9170-x

Villani, D., Sorgente, A., Iannello, P., \& Antonietti, A. (2019). The Role of Spirituality and Religiosity in Subjective Will-Being of Individuals with Different Religious Status. Frontiers in Psychology, 10, 1525. https://doi.org/10.3389/fpsyg.2019.01525

Von Humboldt, S., Leal, I., \& Pimenta, F. (2015). Sense of Coherence, Sociodemographic, Lifestyle, and Health-Related Factors in Older Adults' Subjective Well-Being. International Journal of Gerontology, 9, 15-19. https://doi.org/10.1016/j.ijge.2014.01.007

Yesavage, J. A., Brink, T. L., \& Rose, T. L. (1982). Development and Validation of a Geriatric Depression Scale: A Preliminary Report. Journal of Psychiatric Research, 17, 
37-49. https://doi.org/10.1016/0022-3956(82)90033-4

Yu, Z., \& Chen, L. (2016). Income and Well-Being: Relative Income and Absolute Income Weaken Negative Emotion, but Only Relative Income Improves Positive Emotion. Frontiers in Psychology, 7, 2012. https://doi.org/10.3389/fpsyg.2016.02012

Zarifis, G. K. (2016). Greece and Cyprus. In B. Findsen, M. Formosa (Eds.), International Perspectives on Older Adult Education: Research, Policies and Practices (pp. 157-168). New York: Springer. https://doi.org/10.1007/978-3-319-24939-1_14 